\title{
Produção de forragem e dinâmica de uma pastagem natural submetida a diferentes métodos de controle de espécies indesejáveis e à adubação
}

\section{Luiz Giovani de Pellegrini ${ }^{1^{*}}$, Carlos Nabinger ${ }^{2}$, Mikael Neumann ${ }^{3}$, Paulo César de Faccio Carvalho ${ }^{2}$, Leonardo Araripe Crancio ${ }^{4}$}

\author{
${ }^{1}$ Mestrando da Universidade Federal do Rio Grande do Sul na Área de Zootecnia, Plantas Forrageiras - Porto Alegre - RS - Brasil. \\ 2 Universidade Federal do Rio Grande do Sul - Porto Alegre - RS - Brasil. \\ 3 Universidade Estadual do Centro Oeste - Guarapuava - PR - Brasil. \\ ${ }^{4}$ Engenheiro Agrônomo.
}

RESUMO - Foram testados os efeitos, a médio prazo, de quatro métodos de controle de plantas indesejáveis sobre a produção de forragem e a dinâmica da vegetação em área de pastagem nativa representativa da transição entre a Serra do Sudeste e a Depressão Central do Rio Grande do Sul. Os métodos de controle foram: sem controle; controle mecânico com roçada de primavera; controle mecânico com roçada de outono; e controle químico com herbicida comercial Tordon, à base de Picloram + 2,4-D, na dosagem de $5 \mathrm{~L} / \mathrm{ha}$, associado ou não a fertilização (sem e com adubo). Houve interação entre sistema fertilização e estação do ano e entre método de controle e estação do ano para massa de forragem disponível e de gramíneas. O sistema de fertilização aumentou a massa de forragem disponível $[4.919,0 \mathrm{~kg} / \mathrm{ha}$ de matéria seca (MS)] e de gramíneas $(2.313,1 \mathrm{~kg} / \mathrm{ha}$ de MS). A massa de forragem foi maior na ausência de controle de plantas indesejáveis, que resultou em valores de $5.024,4 ; 3.931,2 ; 3.920,1$ e $3.701,1 \mathrm{~kg} / \mathrm{ha}$ de MS no verão, inverno, outono e na primavera, respectivamente. A frequência de espécies indesejáveis não se altera com a adubação (sem adubo 8,0\% e com adubo 8,4\%) O controle químico promove controle total das espécies indesejáveis e leguminosas nativas. A roçada no outono é mais eficiente no controle das espécies indesejáveis que a roçada de primavera.

Palavras-chave: composição botânica, controle químico, controle mecânico, produção de forragem

\section{Forage production and dynamic of a natural pasture submitted to different control methods of undesirable species and fertilization}

\begin{abstract}
It was tested the effects, in a medium term, of four methods to control undesirable plants on forage production and dynamic of vegetation in a representative area of natural pasture in the transition between Serra do Sudeste and the Depressão Central in Rio Grande do Sul. The control methods were the following: without control, mechanical control with spring mowing, mechanical control with autumn mowing and chemical control with Tordon commercial herbicide based on Picloram $+2,4-\mathrm{D}$ at the dosage $5 \mathrm{~L} / \mathrm{ha}$ associated or not with the fertilization system (with and without fertilizer). There was an interaction between fertilization system and season of the year and interaction between the control method and season of the year for available forage and grass mass. The fertilization system improved the available forage $[4,919.0 \mathrm{~kg} / \mathrm{ha}$ of dry matter $(\mathrm{DM})]$ and mass of grasses $(2,313.1 \mathrm{~kg} / \mathrm{ha}$ of DM). Forage mass was higher in the absence of undesirable plant control, which resulted in values $5,024.4,3,931.3,3,020.1$ and $3,701.1 \mathrm{~kg} / \mathrm{ha}$ of $\mathrm{DM}$ in the summer, winter, autumn and spring, respectively. The frequency of undesirable species is not modified by fertilization $(8.0 \%$ without fertilizer and $8.4 \%$ with fertilizer). Chemical control promotes total control of undesirable species and native leguminous. Autumn mowing is more efficient in controlling undesirable species than spring mowing.
\end{abstract}

Key Words: botanical composition, chemical control, forage production, mechanical control

\section{Introdução}

As pastagens naturais são caracterizadas por grande diversidade ecológica, favorecida por fatores como clima, solo, vegetação e pastejo, que ocasionam produção sazonal, com maior produtividade de forragem na estação quente. Apesar dessa oscilação na produção de forragem, as pastagens naturais são responsáveis pela sustentabilidade da atividade pecuária no Sul do Brasil, uma vez que são o principal recurso forrageiro utilizado na pecuária tradicional. 
Segundo Nabinger (1993), a preservação e o melhoramento desse recurso natural, mais que uma necessidade de ordem técnica e econômica, deve ser compromisso de todos com a conservação de um patrimônio genético de valor inestimável.

Entre as opções de melhoramento e aumento da produção de forragem nesses ecossistemas, destaca-se o controle de espécies indesejáveis, que proporciona aumento da produção da massa de forragem de espécies desejáveis, melhorando a capacidade de suporte da pastagem.

$\mathrm{Na}$ produção animal, entende-se como espécies indesejáveis aquelas plantas que não integram a dieta dos animais de forma contínua, embora pertençam à flora nativa (Nabinger, 1993). Os métodos mecânicos, químicos, biológicos, culturais e manuais podem ser utilizados como alternativas de controle de espécies indesejáveis, desde que sejam economicamente viáveis. O uso do método mecânico (roçadeira) propicia rebrotes mais tenros e menos fibrosos, além de diminuir a competição entre espécies de porte alto (arbustivas) e baixo (gramíneas e leguminosas), permitindo maior desenvolvimento daquelas de melhor qualidade (Nabinger, 1980).

O método químico, mediante a utilização de herbicidas, quando bem empregado, reduz os custos de mão-de-obra e pode eliminar as plantas indesejáveis nas pastagens naturais, dependendo de seu modo de ação. A eliminação da concorrência entre as espécies indesejáveis e as desejáveis, aliada à adubação, pode possibilitar o aumento na capacidade de suporte; além disso, o sucesso de melhoramento das pastagens naturais depende diretamente do seu manejo racional.

Dessa forma, realizou-se este trabalho com o objetivo de avaliar os efeitos de quatro métodos de controle de plantas indesejáveis em pastagem natural associados à adubação na produção de forragem e na dinâmica da vegetação ao longo do ano.

\section{Material e Métodos}

O experimento foi realizado nas instalações da propriedade rural "Casuarinas", no período de dezembro de 2002 a março de 2004, em área de pastagem natural considerada típica da região. A propriedade está situada na zona de transição entre a Depressão Central e a Serra do Sudeste do Rio Grande do Sul, localizada em Cachoeira do Sul, a $30,20^{\circ}$ de latitude Sul, $53,08^{\circ}$ de longitude Oeste, com altitude de $95 \mathrm{~m}$. O clima predominante da região é o Cfa (subtropical umido), conforme classificação de Köppen, com precipação média anual $1.400 \mathrm{~mm}$ e temperatura média anual de $20^{\circ} \mathrm{C}$ (Moreno, 1961).
O solo da área experimental, classificado como argissolo vermelho distrófico típico (EMBRAPA, 1999), foi amostrado em 20/12/2002 e apresentou as seguintes características químicas: $\mathrm{pH}$ em água: 5,$1 ; \mathrm{P}: 2,9 \mathrm{mg} / 1$; MO: 2,8 \%; Al: 0,5 cmol/1; Ca: 2, $1 \mathrm{cmol} / 1 ; \mathrm{Mg}: 1,0 \mathrm{cmol} / 1$; CTC efetiva: $7,7 \mathrm{cmol} / 1$; e saturação de bases: $43 \%$. O local escolhido foi caracterizado, com base em seu histórico de manejo e capacitação de uso nos últimos 40 anos, como isento de interferência, seja oriunda de práticas de fertilização seja de introdução de espécies exóticas ou técnicas de racionalização do pastoreio.

Foram testados os efeitos de quatro métodos de controle de plantas indesejáveis, entre elas, Baccharis trimera, Vernonia nudiflora e Eryngiun horridum. Os métodos foram: sem controle; controle mecânico com roçada de primavera; controle mecânico com roçada de outono; e controle químico com herbicida comercial Tordon, à base de Picloram $+2,4-D$, na dosagem de $5 \mathrm{~L} / \mathrm{h}$ a, associados ou não à adubação com $200 \mathrm{~kg} / \mathrm{ha}$ da mistura $0 \mathrm{~kg} \mathrm{~N}, 90 \mathrm{~kg} / \mathrm{ha} \mathrm{P}_{2} \mathrm{O}_{5}$ e $60 \mathrm{~kg} / \mathrm{ha} \mathrm{K}{ }_{2} \mathrm{O}$ sobre a produção de forragem e dinâmica da vegetação. Cada unidade experimental (subparcela) media $625 \mathrm{~m}^{2} \mathrm{e}$ a área total ocupada pelo experimento foi de $5 \mathrm{ha}$.

A aplicação dos métodos de controle foi realizada em 26/12/2002 para o controle mecânico com roçada de primavera e o controle químico com herbicida, cerca de dez dias após a exclusão da área ao pastejo. O controle mecânico com roçada de primavera foi realizado com roçadeira hidráulica tratorizada (regulagem de altura de corte entre 10 e $15 \mathrm{~cm}$ ) e repetido no dia 22/11/2003, totalizando duas roçadas durante o período experimental. Já o controle mecânico com roçada de outono somente foi aplicado no dia 7/5/2003, obedecendo ao período proposto, de outono; sua aplicação foi nos mesmos moldes do controle mecânico com roçada de primavera. No controle químico com herbicida, utilizou-se um pulverizador pressurizado tratorizado, regulado para aplicação de $270 \mathrm{~L} /$ ha da mistura de água mais o herbicida comercial Tordon (Picloram $+2,4-D$ ) na dose de $5 \mathrm{~L}$ de produto comercial por ha.

As parcelas correspondentes foram divididas ao meio, de modo que uma das metades recebeu adução de cobertura - $\left(200 \mathrm{~kg} / \mathrm{ha}-0 \mathrm{~kg} \mathrm{~N}+90 \mathrm{~kg} / \mathrm{ha} \mathrm{P}_{2} \mathrm{O}_{5}+60 \mathrm{~kg} / \mathrm{ha} \mathrm{K}_{2} \mathrm{O}+\right.$ $150 \mathrm{~kg} /$ ha de N), dividida em duas aplicações na forma de ureia $(45 \%$ de N), uma na fase inicial (25/3/2003), juntamente com a adubação NPK, e a outra no decorrer do período experimental (15/11/2003) — e a outra metade não recebeu adubação, ou seja, foi mantida com os métodos de controle principais.

O período experimental foi de 21/3/2003 a 14/3/2004, período no qual os métodos de controle já tinham sido aplicados. O período foi dividido em quatro fases de 
avaliação: outono (21/3/2003 a 15/5/2003); inverno (2/7/2003 a 14/9/2003); primavera (22/9/2003 a 15/11/2003); e verão (23/12/2003 a 14/3/2004). Durante os perídos de avaliação, os cortes foram realizados em intervalos de 28 dias e os valores expressos na média do número de cortes do período.

Os efeitos dos métodos de controle foram avaliados por meio da biomassa aérea total e de sua composição botânica, determinadas mediante cortes rentes ao solo em quatro quadrados de $0,5 \times 0,5 \mathrm{~m}\left(0,25 \mathrm{~m}^{2}\right)$, alocados aleatoriamente a cada ocasião, em cada unidade experimental. Todo o material presente no local do corte foi recolhido e o total das quatro áreas foi considerado amostra, de modo que a amostra total perfazia $1 \mathrm{~m}^{2}$. Após pesagem da massa total fresca, separou-se uma subamostra representativa de cerca de $0,8 \mathrm{~kg}$, na qual foram separadas manualmente as frações gramíneas, leguminosas, espécies indesejáveis vivas, espécies indesejáveis mortas e material morto das demais espécies. Essas frações foram secas em estufa de ar forçado a $60^{\circ} \mathrm{C}$ por $72 \mathrm{~h}$, para determinação da massa seca de cada componente. Os resultados da massa total e de cada fração foram extrapolados para $\mathrm{kg}$ de matéria seca por ha ( $\mathrm{kg}$ de MS/ha) e a composição botânica foi calculada por meio da participação porcentual de cada fração na massa seca total.

A estimativa da taxa de acúmulo de matéria seca foi avaliada adotando-se o método de acumulação de massa vegetativa dentro de cada período de avaliação. Para obtenção dos valores utilizou-se a massa de forragem (gramíneas + leguminosas) depois do pastejo no período imediatamente anterior menos a massa de forragem (gramíneas + leguminosas) antes do pastejo do período seguinte.

O pastoreio rotacionado dentro da área experimental foi realizado com a finalidade de manter o manejo do pasto em uma altura média de $10 \mathrm{~cm}$, utilizando-se da ocupação de animais em períodos de 1 a 1,5 dia por bloco de avaliação. Para isso, cada bloco foi isolado com cerca elétrica, objetivando o pastejo somente no seu interior. A categoria animal utilizada para realização do pastejo foram vacas vazias, com peso vivo médio de $450 \mathrm{~kg}$ na primavera e verão. Já no outono e inverno foram vacas com cria ao pé, com peso vivo médio de vaca e terneiro de $520 \mathrm{~kg}$. Como o objetivo era realizar o pastejo o mais rápido possível utilizaram-se as categorias com maior número de animais disponíveis na propriedade.

Foram realizados quatro pastejos em todo o período experimental, sendo um por estação. Estes pastejos sempre que realizados dependiam da disponibilidade dos animais da propriedade, está foi à razão por não ter ocorrido pastejo mais vezes.
O delineamento experimental utilizado para avaliar os parâmetros massa de forragem, taxa de acumulação média diária e composição botânica da pastagem foi o de blocos casualizados com parcelas subdivididas e com médias repetidas no tempo em um arranjo fatorial $4 \times 2 \times 4$ (quatro métodos de controle de espécies indesejáveis associado à adubação ou não e quatro estações do ano), com quatro repetições. A comparação das médias dos métodos de controle foi realizada pelo teste Tukey para efeito principal e pelo teste Pdiff em casos de interação entre método de controle, estação do ano e adubação, ambos em nível de significância de 5 \% (SAS, 1993), sendo utilizado o seguinte modelo matemático:

$$
\begin{gathered}
\mathrm{Y}_{\mathrm{ijk}}=\mu+\mathrm{MC}_{\mathrm{i}}+\mathrm{B}_{\mathrm{j}}+(\mathrm{MC} * \mathrm{~B})_{\mathrm{ij}}+\mathrm{SF}_{\mathrm{k}}+(\mathrm{MC} * \mathrm{SF})_{\mathrm{ik}}+\mathrm{EA}_{1} \\
+(\mathrm{MC} * \mathrm{EA})_{\mathrm{il}}+(\mathrm{SF} * \mathrm{EA})_{\mathrm{kl}}+\mathrm{E}_{\mathrm{ijklm}},
\end{gathered}
$$

em que: $\mathrm{Y}_{\mathrm{ijk}}=$ variável dependente; $\mu=$ média das observações; $\mathrm{MC}_{\mathrm{i}}=$ efeito dos métodos de controle de índice $i$, em que 1 = sem controle; 2 = controle mecânico com roçada de primavera; 3 = controle mecânico com roçada de outono; 4 = controle químico com herbicida; $\mathrm{B}_{\mathrm{j}}=$ efeito do bloco de índice $\mathrm{j} ;(\mathrm{MC} * \mathrm{~B})_{\mathrm{ij}}=$ efeito da interação ente método de controle de índice i e bloco de índice j (Erro a); $\mathrm{SF}_{\mathrm{k}}=$ efeito do sistema de fertilização de índice $\mathrm{k}$, em que $1=$ sem adubação; e 2 = com adubação; $(\mathrm{MC} * \mathrm{SF})_{\mathrm{ik}}=$ efeito da interação entre método de controle de índice i e sistema de fertilização de índice k; $\mathrm{EA}_{1}=$ efeito da estação do ano de índice 1 , em que 1 = outono; 2 = inverno; 3 = primavera; $\mathrm{e}$ $4=$ verão; $(\mathrm{MC} * \mathrm{EA})_{\mathrm{il}}=$ efeito da interação entre método de controle de índice i e estação do ano de índice $1 ;(\mathrm{SF} * \mathrm{EA})_{\mathrm{kl}}=$ efeito da interação entre sistema de fertilização de índice $\mathrm{k}$ e estação do ano de índice $1 ; \mathrm{E}_{\mathrm{ijklm}}=$ efeito do erro aleatório associado a cada observação (Erro b). A interação $(\mathrm{MC} * \mathrm{SF} * \mathrm{EA})_{\mathrm{ikl}}$ também foi testada, no entanto, em razão da baixa magnitude, foi removida do modelo estatístico.

\section{Resultados e Discussão}

Para os parâmetros massa de forragem disponível, de gramíneas verdes secas e taxa de acúmulo, houve interação significativa entre sistema de fertilização e estação do ano. Já para a massa de leguminosas verdes secas, não houve interação significativa (Tabelas 1 e 4).

A massa de forragem disponível e a massa de gramíneas verdes secas no período de verão com adubação foram superiores às demais associações. A menor $(\mathrm{P}<0,05)$ massa de forragem disponível foi observada no período de inverno com adubação e não diferiu estatisticamente da obtida no inverno e primavera sem adubação e na primavera com adubação (Tabela 1) 
Tabela 1- Comportamento de uma pastagem natural submetida ao controle de espécies indesejáveis com ou sem fertilização

\begin{tabular}{|c|c|c|c|c|c|}
\hline \multirow[t]{2}{*}{ Sistema de fertilização } & \multicolumn{4}{|c|}{ Período de avaliação } & \multirow[b]{2}{*}{ Média } \\
\hline & Outono & Inverno & Primavera & Verão & \\
\hline & \multicolumn{5}{|c|}{ Massa de forragem disponível (kg/ha de MS) } \\
\hline \multirow[t]{2}{*}{ Com adubação } & $3771,2 b$ & $3128,3 \mathrm{~d}$ & $3309,5 \mathrm{~d}$ & $4919,0 \mathrm{a}$ & 3782,0 \\
\hline & \multicolumn{5}{|c|}{ Massa de gramíneas verdes secas (kg/ha de MS) } \\
\hline Sem adubação & $980,4 \mathrm{f}$ & $973,1 \mathrm{f}$ & $1253,6 \mathrm{~d}$ & $1800,7 b$ & 1252,0 \\
\hline Com adubação & \multicolumn{5}{|c|}{ Massa de leguminosas verdes secas (kg/ha de MS) } \\
\hline Sem adubação & 211,3 & 93,1 & 96,0 & 343,7 & $186,0 \mathrm{~A}$ \\
\hline \multirow[t]{2}{*}{ Com adubação } & 189,5 & 87,7 & 82,3 & 434,1 & $198,4 \mathrm{~A}$ \\
\hline & \multicolumn{5}{|c|}{ Taxa de acúmulo $(\mathrm{kg} / \mathrm{ha} / \mathrm{dia}$ de $\mathrm{MS})$} \\
\hline Sem adubação & $25,7 \mathrm{c}$ & $21,3 \mathrm{c}$ & $44,7 \mathrm{~b}$ & $15,9 \mathrm{c}$ & 26,9 \\
\hline Com adubação & $25,7 \mathrm{c}$ & $15,4 \mathrm{c}$ & $62,1 \mathrm{a}$ & $24,2 \mathrm{c}$ & 31,9 \\
\hline
\end{tabular}

a, b, c, d, e, f - Médias seguidas de letras minúsculas diferentes diferem entre si $(\mathrm{P}<0,05)$ pelo teste Pdiff.

A - Médias seguidas de letras maiúsculas diferentes na coluna, conforme o parâmetro avaliado e sistema de fertilização, diferem entre si (P<0,05) pelo teste Tukey.

Quando analisada a taxa de acumulação média diária de forragem (Tabela 1), as maiores taxas de acúmulo $(\mathrm{P}<0,05)$ foram observadas no período de primavera com $(62,1 \mathrm{~kg} / \mathrm{ha} / \mathrm{dia}$ de MS) e sem adubação (44,7 kg/ha/dia de MS), valores que diferiram estatisticamente entre si e dos demais valores apresentados. Estes resultados corroboram os obtidos por Thurow et al. (2009), que também observaram taxa de acúmulo superior para o período de primavera em relação aos demais. O maior acúmulo refletiu em maior massa de forragem disponível no período subsequente. Nos dois casos, o reflexo foi constatado no período de verão para massa de forragem com adubação, cujo valor foi superior aos demais. A massa de forragem do mesmo período sem adubação diferiu daquela obtida com adubação, mas não foi influenciada pela adubação no período de outono (Tabela 1).

Os demais valores de taxa de acúmulo nos períodos de avaliação não diferiram estatisticamente entre si e foram de 25,$7 ; 25,7 ; 24,2 ; 21,3 ; 15,9 ;$ e $15,4 \mathrm{~kg} / \mathrm{ha} / \mathrm{dia}$ de MS no outono sem adubação, no outono e no verão (com adubação), no inverno e no verão (sem adubação) e no inverno (com adubação), respectivamente.

A porcentagem de gramíneas verdes e a porcentagem de material morto diferiu significativamente entre os manejos com e sem adubação, enquanto a porcentagem de leguminosas e de indesejáveis vivas (Tabela 2), bem como a massa de leguminosas verdes secas, não apresentaram diferença estatística (Tabela 1). Para porcentagem de indesejáveis mortas na pastagem, houve interação significativa entre método de controle e estação do ano, ao passo que, para porcentagens de gramíneas, de leguminosas e de material morto, não houve interação significativa (Tabela 2).

A participação de material morto obtida sem adubação foi de $53,9 \%$, superior à observada com a adubação, $48,8 \%$
(Tabela 2). De forma semelhante, Moojen (1991) encontrou redução na porcentagem de material morto com o aumento dos níveis de adubação em resposta à maior produção de forragem.

A adubação não influenciou os valores da massa de forragem de leguminosas encontrados neste trabalho. Resultados contrários foram encontrados por Mufarrege et al. (1972), que constataram o favorecimento das leguminosas com adubação fosfatada isolada, aumentando em 13,6\% sua participação na pastagem. No entanto, quando a adubação com fósforo foi associada à adubação nitrogenada, encontraram redução da presença de leguminosas, como resultado do favorecimento das gramíneas.

A interação entre método de controle e estação do ano influenciou as massas de forragem, de gramíneas verdes secas e de leguminosas verdes secas, a taxa de acúmulo, a porcentagem de gramíneas, de leguminosas, de indesejáveis, de material morto e de espécies indesejáveis mortas na composição da pastagem (Tabela 3 ).

A influência da interação entre métodos de controle e período de avaliação sobre a massa de forragem de leguminosas comprova a maior participação no período de verão controle mecânico com roçada de outono, sem controle e controle mecânico com roçada de primavera (Tabela 3). Com o controle químico com herbicida, o maior valor foi observado no inverno (17,2 kg/ha de MS) e, assim como nos demais períodos, não são expressivos se comparados àqueles obtidos com os demais métodos de controle de espécies indesejáveis. No outono e na primavera, o controle mecânico com roçada na primavera resultou em massa de 292,6 e $130,8 \mathrm{~kg} / \mathrm{ha}$ de MS, enquanto, com o controle químico com herbicida, os valores foram de 0,0 e 10,2 kg/ha de MS nos mesmos períodos. No inverno, a massa de 
Tabela 2 - Composição botânica de uma pastagem natural submetida ao controle de espécies indesejáveis com ou sem fertilização

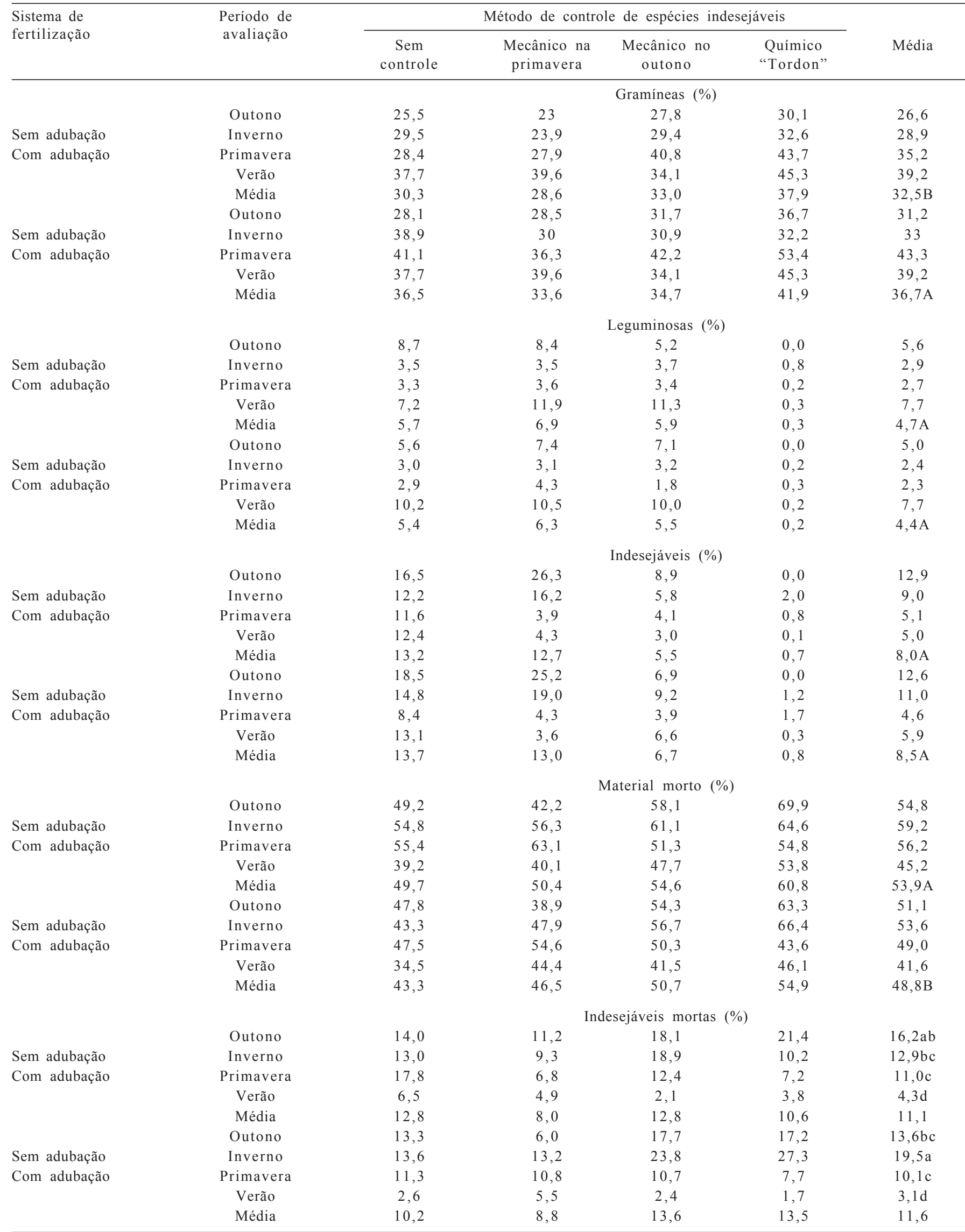

a, b, c, d - Médias seguidas de letras minúsculas diferentes diferem entre si $(\mathrm{P}<0,05)$ pelo teste Pdiff.

A, B - Médias seguidas de letras maiúsculas diferentes na coluna, conforme o parâmetro avaliado e o sistema de fertilização, diferem entre si (P $<0,05)$ pelo teste Tukey. 
forragem de leguminosas obtida com o controle mecânico com roçada na primavera e com roçada no outono $(101,0 \mathrm{~kg} / \mathrm{ha}$ de MS) foi inferior à obtida sem controle de espécies indesejáveis (142,5 kg/ha de MS), mas superior à observada com controle químico com herbicida, embora a participação de leguminosas seja maior no inverno. Os valores comprovam o efeito negativo do controle químico com herbicida sobre a disponibilidade de leguminosas na pastagem.
$\mathrm{Na}$ análise da composição botânica de leguminosas (Tabela 3), confirmou-se a maior participação dessas espécies no período de verão com o controle mecânico com roçada na primavera, o controle mecânico com roçada no outono e a ausência de controle $(11,2 ; 10,7$; e $8,7 \%$, respectivamente), enquanto, com o controle químico com herbicida, a participação foi de apenas $0,3 \%$. Os valores encontrados nos demais períodos $(0,0 ; 0,3$ e $0,5 \%$ para

Tabela 3 - Comportamento e composição botânica de uma pastagem natural submetida ao controle de espécies indesejáveis

\begin{tabular}{|c|c|c|c|c|}
\hline \multirow[t]{2}{*}{ Período de avaliação } & \multicolumn{4}{|c|}{ Método de controle de espécies indesejáveis } \\
\hline & Sem controle & Mecânico na primavera & Mecânico no outono & Químico "Tordon" \\
\hline & \multicolumn{4}{|c|}{ Massa de forragem disponível (kg/ha de MS) } \\
\hline Inverno & $3931,2 \mathrm{c}$ & $3265,5 \mathrm{def}$ & $2910,4 \mathrm{f}$ & $2899,4 \mathrm{f}$ \\
\hline Primavera & $3701,1 \mathrm{~cd}$ & $3233,7 \mathrm{ef}$ & $3317,5 \mathrm{def}$ & $3225,3 \mathrm{ef}$ \\
\hline Verão & $5024,5 \mathrm{a}$ & $3588,3 \mathrm{cde}$ & $4438,8 b$ & $4534,3 \mathrm{~b}$ \\
\hline Inverno & $1365,7 \mathrm{de}$ & $884,6 \mathrm{~g}$ & $861,8 \mathrm{~g}$ & $945,4 \mathrm{~g}$ \\
\hline Primavera & $1388,4 \mathrm{de}$ & $1102,4 \mathrm{fg}$ & $1463,4 \mathrm{cde}$ & $1660,3 \mathrm{bc}$ \\
\hline \multirow[t]{2}{*}{ Verão } & $2432,5 \mathrm{a}$ & $1623,0 \mathrm{bcd}$ & $1827,7 \mathrm{~b}$ & $2344,5 \mathrm{a}$ \\
\hline & \multicolumn{4}{|c|}{ Massa de leguminosas verdes secas (kg/ha de MS) } \\
\hline Outono & $286,3 b$ & $292,6 b$ & $222,8 \mathrm{bc}$ & $0,0 \mathrm{e}$ \\
\hline Verão & \multicolumn{4}{|c|}{ Taxa de acúmulo (kg/ha/dia de MS) } \\
\hline Outono & $17,3 \mathrm{~d}$ & $16,8 \mathrm{~d}$ & $40,0 \mathrm{~b}$ & $28,8 \mathrm{bcd}$ \\
\hline Inverno & $17,9 \mathrm{~d}$ & $22,5 \mathrm{~cd}$ & $16,5 \mathrm{~d}$ & $16,4 d$ \\
\hline Primavera & $60,0 \mathrm{a}$ & $36,2 \mathrm{bc}$ & $56,8 \mathrm{a}$ & $60,5 \mathrm{a}$ \\
\hline \multirow[t]{2}{*}{ Verão } & $23,0 \mathrm{~cd}$ & $19,6 \mathrm{~d}$ & $22,3 \mathrm{~cd}$ & $15,3 \mathrm{~d}$ \\
\hline & \multicolumn{4}{|c|}{ Gramíneas $(\%)$} \\
\hline Outono & $26,8 \mathrm{gh}$ & $25,8 \mathrm{~h}$ & $29,8 \mathrm{fgh}$ & 33,4 defg \\
\hline Inverno & $34,2 \mathrm{cdef}$ & $27,0 \mathrm{gh}$ & $30,2 \mathrm{fgh}$ & $32,4 \mathrm{ef}$ \\
\hline Primavera & $34,8 \mathrm{cdef}$ & $32,1 \mathrm{efg}$ & $41,5 \mathrm{~b}$ & $48,6 \mathrm{a}$ \\
\hline \multirow[t]{2}{*}{ Verão } & $38,7 \mathrm{bcd}$ & $39,6 b c$ & $35,9 \mathrm{cde}$ & $47,8 \mathrm{a}$ \\
\hline & \multicolumn{4}{|c|}{ Leguminosas $(\%)$} \\
\hline Outono & $7,2 \mathrm{~cd}$ & $7,9 \mathrm{~cd}$ & $6,2 \mathrm{~d}$ & $0,0 \mathrm{~g}$ \\
\hline Verão & \multicolumn{4}{|c|}{ Material morto (\%) } \\
\hline Outono & $48,5 \mathrm{efg}$ & $40,5 \mathrm{hi}$ & $56,2 \mathrm{~cd}$ & $66,6 \mathrm{a}$ \\
\hline Inverno & $49,0 \mathrm{efg}$ & $52,1 \mathrm{cde}$ & $58,9 \mathrm{bc}$ & $65,5 \mathrm{ab}$ \\
\hline Primavera & $51,5 \mathrm{def}$ & $58,8 \mathrm{bc}$ & $50,8 \mathrm{def}$ & 49,2 defg \\
\hline \multirow[t]{2}{*}{ Verão } & $36,9 \mathrm{i}$ & $42,3 \mathrm{ghi}$ & $44,6 \mathrm{fgh}$ & $50,0 \mathrm{def}$ \\
\hline & \multicolumn{4}{|c|}{ Indesejáveis mortas (\%) } \\
\hline Outono & $13,7 \mathrm{bcde}$ & $8,6 \mathrm{defg}$ & $17,9 \mathrm{abc}$ & $19,3 \mathrm{ab}$ \\
\hline Inverno & 13,3 bcde & $11,3 \mathrm{def}$ & $21,4 \mathrm{a}$ & $18,7 \mathrm{ab}$ \\
\hline Primavera & $14,5 \mathrm{bcd}$ & $8,8 \mathrm{defg}$ & $11,5 \mathrm{cdef}$ & $7,5 \mathrm{efg}$ \\
\hline Verão & $4,5 \mathrm{~g}$ & $5,2 \mathrm{fg}$ & $2,3 \mathrm{~g}$ & $2,7 \mathrm{~g}$ \\
\hline
\end{tabular}

a, b, c, d, e, f, g, h, i - Médias seguidas de letras minúsculas diferentes diferem entre si $(\mathrm{P}<0,05)$ pelo teste Pdiff. 
outono, primavera e inverno, respectivamente) confirmam o efeito negativo desses métodos de controle de espécies indesejáveis sobre as espécies de leguminosas. Esses resultados comprovam ainda a necessidade de um rigoroso cuidado na escolha do método de controle de espécies indesejáveis a ser aplicado, uma vez que alguns métodos podem prejudicar a participação de espécies com papel importantíssimo nos ecossistemas pastoris. São espécies que melhoram a dieta do animal, a eficiência de captação de energia solar e ainda disponibilizam as gramíneas em consórcio nitrogênio.

De acordo com Moojen (1991), em pastagem natural normalmente a maior participação de leguminosas ocorre no período de verão. Mufarrege et al. (1972), no entanto, em pastagem nativa melhorada, observaram alta participação de leguminosas, tanto na primavera como no verão. Heringer \& Jacques (2002) observaram tendência de as leguminosas nativas contribuírem mais nas áreas melhoradas e roçadas.

Carámbula et al. (1995) ressaltaram o efeito do herbicida à base de Picloram + 2,4-D (Tordon) na redução de leguminosas na composição da pastagem natural, já que esse herbicida é seletivo às gramíneas. Essa constatação é contrária à de Allegri (1978), que não observou efeito supressor desse herbicida no desenvolvimento e/ou na sobrevivência das leguminosas nativas.

Com a interação entre métodos de controle e estação do ano, o maior valor da massa de forragem foi obtido sem controle no verão $(5.024,4 \mathrm{~kg} / \mathrm{ha}$ de MS). A massa de forragem nos demais períodos (inverno $3.931,2 \mathrm{~kg} / \mathrm{ha}$ de MS, outono $3.920,1 \mathrm{~kg} / \mathrm{ha}$ de MS e primavera $3.701,1 \mathrm{~kg} / \mathrm{ha}$ de MS) também foi maior neste tratamento e justifica-se pela maior participação de espécies indesejáveis (Tabela 2), independentemente do período $(17,5 ; 13,5 ; 10,0$ e $12,8 \%$ para outono, inverno, primavera e verão, respectivamente). Essas espécies dificultam a acessibilidade da forragem aos animais, por razões estruturais dessas plantas. A carqueja, por exemplo, tem grande número de hastes e ocupa grandes áreas; várias plantas juntas formam uma barreira a ser vencida pelos animais, uma vez que, quando baixam a cabeça para pastejar, podem encostar os olhos ou as narinas nestas plantas, o que acaba machucando e levando os animais a buscar áreas mais limpas, de mais fácil acesso à forragem.

Da mesma forma, em áreas com presença de caraguatá, os espinhos presentes nas folhas das plantas formam uma barreira natural de proteção da planta, que, em grande número, acabam cobrindo grandes áreas da pastagem, também dificultando o acesso a forragem pelos animais. Consequentemente, os animais procuram excluir essas áreas ao pastejo proporcionando resíduos maiores.
A menor massa de forragem disponível foi observada no inverno com a aplicação do controle mecânico com roçada no outono, pois a roçada removeu parte do estrato superior da pastagem, eliminando grande parte das espécies indesejáveis (Tabela 3) e diminuindo a massa de forragem ( $\mathrm{kg} / \mathrm{ha}$ de MS). Mesmo assim, na primavera, não houve diferença $(\mathrm{P}>0,05)$ entre o controle mecânico com roçada no outono (3.317,5 kg/ha de MS) e o controle químico, tanto no inverno (2.899,4 kg/ha de MS) como na primavera (3.225,3 kg/ha de MS). A menor massa de forragem associa-se ainda ao fato de que a taxa de acúmulo do período não foi elevada $(16,5 \mathrm{~kg} / \mathrm{ha} / \mathrm{dia}$ de MS) em comparação à observada nas demais épocas.

A massa de gramíneas verdes secas (Tabela 3 ) foi maior no verão, no caso da ausência de controle de espécies indesejáveis (2.432,5 kg/ha de MS) e da aplicação de controle químico com herbicida (2.344,5 kg/ha de MS). Os valores foram similares entre esses dois métodos de controle, mas diferiram dos obtidos com os demais métodos de controle.

As maiores taxas de acúmulo foram observadas na primavera (Tabela 3 ) para os métodos sem controle, com controle mecânico no outono e com controle químico, que não diferiram entre si $(60,0 ; 56,8 ;$ e $60,5 \mathrm{~kg} / \mathrm{ha} / \mathrm{dia}$ de MS, respectivamente). A menor taxa de crescimento na primavera verificada com o controle mecânico na primavera pode estar relacionada ao fato de que a roçada nesta época prejudica o desenvolvimento das plantas, em virtude da eliminação de parte da área foliar. Por outro lado, Moojen (1991) também observou baixas taxas de acúmulo nessa estação mesmo sem roçada e, para os períodos de verão, outono e primavera, verificou taxas médias de crescimento de 27,$8 ; 10,6$; e $10,9 \mathrm{~kg} / \mathrm{ha} /$ dia de MS, respectivamente. Esse relatou ainda que campos naturais submetidos à adubação apresentaram taxa de acúmulo médio anual (23 kg/ha/dia de MS) superior à do campo não adubado $(10,7 \mathrm{~kg} / \mathrm{ha} / \mathrm{dia}$ de MS $)$.

A aplicação de herbicida foi efetiva no controle das espécies indesejáveis, uma vez que as porcentagens de participação não passaram de 1,6\% no inverno (Tabela 3 ). Ao mesmo tempo em que foi efetiva no controle das espécies indesejáveis, foi muito prejudicial à participação de leguminosas na composição florística da pastagem, reduzindo a porcentagem de participação dessa espécie a zero no outono e a porcentagens insignificantes nos demais períodos. Com a aplicação do método mecânico com roçada no outono, houve redução das espécies indesejáveis nesse período, uma vez que o método de controle foi aplicado no mesmo período de senescência das plantas. Da mesma forma, a redução das espécies indesejáveis na primavera com a aplicação do controle mecânico na primavera também foi 


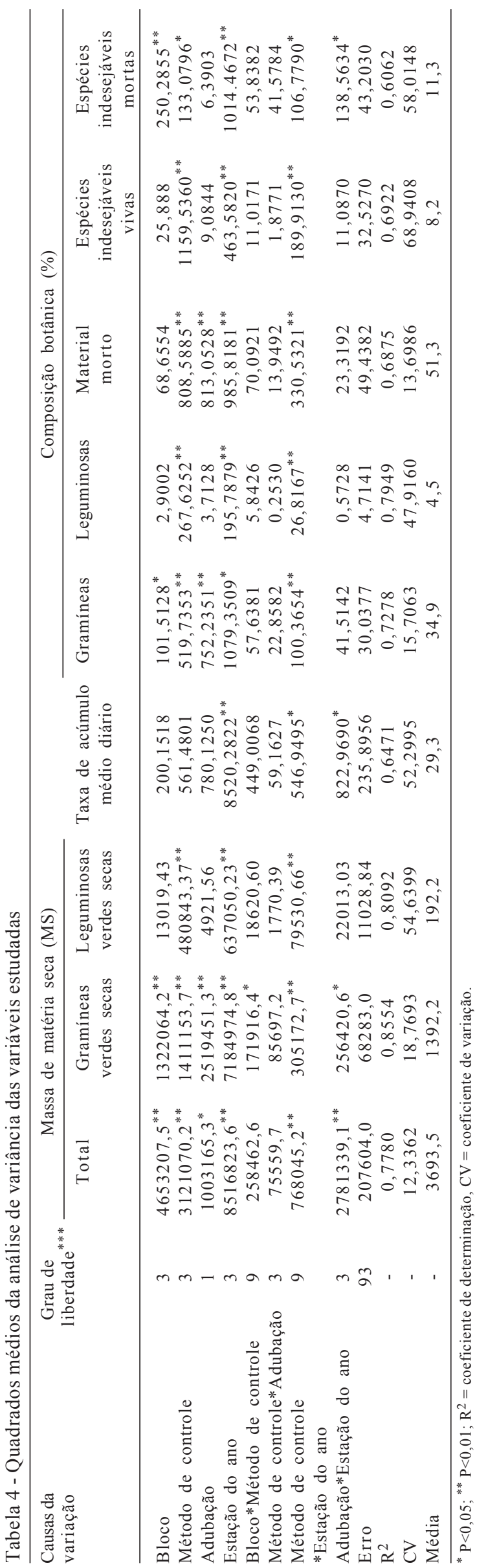

consequência da aplicação do método de controle, uma vez que, nesse período, a aplicação da roçada estava ocorrendo pela segunda vez. Quando a porcentagem de espécies indesejáveis foi observada no mesmo período, confirmou-se a maior eficiência do controle mecânico no outono, uma vez que a roçada foi aplicada somente nesse período e seus efeitos se estenderam até a primavera. Como o período experimental foi muito curto é importante necessidade de dar continuidade as avaliações para confirmação destes resultados.

Alguns autores, no entanto, como Mas et al. (1997), trabalharam com a interação de quatro datas iniciais de cortes, três números de cortes (um, dois e quatro) e três intervalos (três, seis e nove meses) no controle de caraguatá e comprovaram que, independentemente do número e da frequência, quando os cortes foram realizados no outono, ocorreram menores valores de cobertura da espécie, a qual diminuiu de $70 \%$ para $20 \%$, confirmando que a época em que ocorrem as roçadas é mais importante que o número e a frequência dos cortes.

Carámbula et al. (1995), estudando o efeito da época de cortes sobre o caraguatá, concluíram que os cortes realizados no outono são mais eficientes no controle dessa espécie. Nuñez \& Del Puerto (1988) também citaram essa época como a mais eficiente no controle de carqueja.

\section{Conclusões}

O controle químico proporciona controle total das espécies indesejáveis e eliminação das leguminosas nativas até um ano após aplicação. $\mathrm{O}$ controle mecânico não tem controle efetivo das espécies indesejáveis e deve ser aplicado no outono. A fertilização aumenta a massa total e a massa de gramíneas verdes secas, mas não afeta a participação das espécies indesejáveis, tampouco a eficiência dos métodos de controle.

\section{Referências}

ALLEGRI, M. Mejoramiento de pasturas naturales. Control de malezas. In: REUNION DEL GRUPO TECNICO REGIONAL DEL CONO SUR EN MEJORAMIENTO Y UTILIZACIÒN DE LOS RECURSOS FORRAJEROS DEL AREA TROPICAL Y SUBTROPICAL. 1., 1978, Mercedes. Informe... Montevideo: IICA, 1978. p.120-132. CARÁMBUla, M.; AYALA, W.; BERMÚEZ, R. et al. Control de Cardilla. Montevideo: Instituto Nacional de Investigación Agropecuaria, 1995. 9p. (Serie Técnica, 57).

EMPRESA BRASILEIRA DE PESQUISA AGROPECUÁRIA EMBRAPA. Centro Nacional de Pesquisa do Solo - CNPS. Sistema Brasileiro de Classificação de solos. Rio de Janeiro: EMBRAPA, 1999. 412p.

HERINGER, I.; JACQUES, A.V.A. Composição florística de uma pastagem natural submetida à queima e manejos alternativos. Ciência Rural, v.32, n.2, p.315-321, 2002. 
MAS, C.; BERMÚDEZ, R.; AYALA, W. Efectos de distintos momentos y frecuencias de corte em el control de cardilla (Eryngium horridum). In: INSTITUTO NACIONAL DE INVESTIGACIÓN AGROPECUARIA, INIA. Pasturas y Producción animal en areas de ganaderia extensiva. 2.ed. Montevideo: INIA, 1997. p.135-139. (Serie Tecnica, 13).

MOOJEN, E. L. Dinâmica e potencial produtivo de uma pastagem nativa do Rio grande do Sul submetida a pressões de pastejo, épocas de diferimento e níveis de adubação. 1991. 172f. Tese (Doutorado em Zootecnia) Faculdade de Agronomia/Universidade Federal do Rio Grande do Sul, Porto Alegre.

MOREno, J.A. Clima do Rio Grande do Sul. Porto Alegre: Secretaria da Agricultura, 1961. 41p.

MUFARREGE, D.J.; PALlARES, O.R.; SALAVERRY, F. et al. Fertilization de campo natural con nitrogeno y fosforo. Mercedes: INTA. Estacion Experimental Agropecuaria, 1972. 20 p.
NABINGER, C. Técnicas de melhoramento de pastagens naturais no Rio Grande do Sul. In: SEMINÁRIO SOBRE PASTAGENS - "DE QUE PASTAGENS NECESSITAMOS", 1980, Porto Alegre. Anais... Porto Alegre: Farsul, 1980. p.28-58.

NABINGER, C. Prefácio. In: Campo nativo: melhoramento e manejo. Federação dos Clubes de Integração e Troca de Experiências, Federacite IV. Porto Alegre: Caramuru, 1993.

NUÑEZ, H.; del PUERTO, O. Biología de Baccharis trimera. In: REUNIÓN DEL GRUPO TÉCNICO REGIONAL DEL CONO SUR EM MEJORIAMENTOS Y UTILIZACIÓN DE LOS RECURSOS FORRAJEROS DEL AREA TROPICAL Y SUBTROPICAL, 9., 1988, Tacuarembó. Anais... Tacuarembó: Grupos Campos y Chacos, 1988. p.99-102.

STATISTICAL ANALYSIS SYSTEM - SAS. SAS Language reference. Version 6. Cary: SAS Institute, 1993. 1042p.

THUROW, J.M.; NABINGER, C.; CASTILhOS, Z.M.Z. et al. Estrutura da vegetação e comportamento ingestivo de novilhos em pastagem natural do Rio Grande do Sul. Revista Brasileira de Zootecnia, v.38, n.5, p.818-826, 2009. 